\title{
HYDRATION GIBBS ENERGIES OF NUCLEIC ACID BASES DETERMINED BY GIBBS ENERGY PERTURBATION, CONTINUOUS AND HYBRID APPROACHES
}

\author{
Jindřich FANFRLÍK ${ }^{1}$, Jaroslav RejNeK ${ }^{2}$, Michal HANUs ${ }^{3}$ and Pavel HobZA ${ }^{4, *}$ \\ Institute of Organic Chemistry and Biochemistry, Academy of Sciences of the Czech Republic, \\ and Center for Biomolecules and Complex Molecular Systems, 16610 Prague 6, Czech Republic; \\ e-mail: ${ }^{1}$ fanfrlik@uochb.cas.cz, ${ }^{2}$ rejnek@uochb.cas.cz, ${ }^{3}$ mhanus@faculty.unyp.cz, \\ ${ }^{4}$ hobza@uochb.cas.cz
}

Received June 9, 2005

Accepted September 6, 2005

The hydration Gibbs energies of adenine, cytosine, guanine, thymine, uracil and isoguanine are determined by the molecular dynamics-thermodynamic integration method (MD-TI) and using continuous COSMO and hybrid models. The role of solvents in the COSMO model is described by permittivity and by combining the permittivity and specific hydration of single water molecules placed on the energetically most probable position in the hybrid model. The hybrid model describes hydration similarly to the COSMO model; both the continuous methods are in good agreement with the MD-TI method. Differences are small and the use of both models can be recommended.

Keywords: COSMO; Hybrid model; Hydration; Gibbs energy; Nucleobases tautomers; Purines; Pyrimidines; Thermodynamic integration; Molecular dynamics; Tautomerism.

Contemporary computational chemistry has become very powerful in investigating the properties of molecules in the gas phase. Unfortunately, the gas phase is not biologically relevant. The study of chemical systems in the condensed phase, which is much closer to the natural environment, is far more difficult. This paper compares several theoretical procedures for determining of hydration Gibbs energies $\left(\Delta G_{H Y D}\right)$ and, as a result of this comparison, we recommend the most appropriate solution. Both accuracy and time dependence of the methods is taken into account.

One of the "most standard" methods - molecular dynamics (MD) - deals with a large number of explicit water molecules, but averaging a large number of configurations (sampling of the phase space) is very timedemanding. Moreover, only the empirical potential (force field) is reliable at the moment. Another explicit approach relies on a limited amount (1-10) of solvent molecules fully described by the most accurate quantum 
chemical methods ${ }^{1,2}$. This approach corresponds to gas-phase hydration but is less appropriate for liquid phase. The effect of an infinite number of hydration shells could easily be described by continuous methods like PCM or COSMO (C-PCM $)^{3-6}$, but only under the assumption that the system does not exhibit specific hydration (i.e., one or a small number of water molecules tightly bind to the system and affect its properties). Unfortunately, this is exactly the case of nucleic acid (NA) bases and other biomolecules. The natural choice for such calculations is the hybrid/discrete model that incorporates explicit hydration into continuous methods. Here, the main problem of the application concerns criteria that identify the need for specific water molecules and then select the proper number of explicit water molecules. Various criteria $(\Delta E, \Delta G)$ were suggested ${ }^{7}$.

Another minor problem is that parameters specifically derived for continuum methods are also used in the hybrid model. These parameters partially compensate the solvation-first-shell effect and applying them in the presence of the specific water molecules could overestimate hydration ${ }^{7,8}$.

The aim of this paper is to investigate the reliability of bare/hybrid methods (only with one explicit water) for nucleic acid bases - adenine, cytosine, guanine, thymine, uracil, isoguanine - and provide a simple, rapid, solid and reliable method for the evaluation of Gibbs energy of hydration applicable to NA bases and other biosystems. We extensively use quantum mechanical (QM) and molecular dynamics-thermodynamic integration (MD-TI) results published in our laboratory in the last three years ${ }^{9-12}$ as well as new data, in particular the calculations of hybrid model criteria.

Our recent studies on cytosine $\mathrm{e}^{13}$, guanine $\mathrm{e}^{10}$, adenine $\mathrm{e}^{11}$, thymine $\mathrm{e}^{12}$, ura $\mathrm{Cil}^{12}$ and even other literature data ${ }^{14}$ have shown that bulk water plays an important role in the stability of NA tautomers and can even change the relative stabilities of various tautomers in comparison with the gas phase. The canonical form of cytosine (being, in the gas phase, the first local minimum destabilized over the global minimum by about $2 \mathrm{kcal} / \mathrm{mol}$ ) becomes clearly favored compared with other structures in water environment ${ }^{13}$. The canonical form of guanine in the gas phase was energetically comparable with three other tautomers. Surprisingly, bulk water stabilized unusually rare tautomers (with very large dipole moments) which were extremely disfavored energetically in the gas phase (by about $20 \mathrm{kcal} / \mathrm{mol})^{10}$. In the case of adenine, the polar solvent also reduced the gap between the canonical form (global minimum) and the first two local minima resulting in the coexistence of these three forms, as predicted ${ }^{11}$. This conclusion was fully confirmed by NMR experiments in DMSO ${ }^{11}$. Finally, we refused all "evi- 
dence" about the uracil enol form and we fully confirmed the dominance of the canonical form in all environments ${ }^{12}$.

Similarly to our previous studies, the effect of bulk water was estimated by two entirely different methods which considered the solvent as a continuum or an explicit/discrete medium. It must be mentioned that neither of the methods used is parameter-free and both methods have advantages and disadvantages. The main problem is that the effect of specific hydration cannot be described properly by either approach. Molecular dynamic/ empirical potential simulations (in the present versions) that are adopted to describe discrete solvents cannot account for important QM effects such as electron and charge transfers or polarization. On the other hand, quantum chemical methods used in the self-consistent reaction-field calculations of isolated solute do not consider the specific electrostatic effects of most strongly bound water molecules. Combining both approaches seems to be a natural solution. The hybrid approach, where solute molecules with a small number of the most strongly interacting water molecules are placed in the continuum solvent, has attracted a lot of attention ${ }^{3,15-18}$. There are some uncertainties, the most critical one concerns how to define the criterion when specific hydration should be considered and how many water molecules should be taken into account. Further, the performance of hybrid models was not sufficiently tested and compared with benchmark MD results. Our aim was to answer these questions and find a method which would be easy to apply to much larger systems (e.g. fragments of DNA) than the present isolated bases and which would provide reliable estimates of hydration Gibbs energies.

\section{METHODS}

Quantum chemical calculations. The gas-phase geometry characteristics of NA bases was determined using the RI-MP2 procedure ${ }^{19}$ with a TZVPP [5s3p2d1f/3s2p1d] basis set. Gas-phase Gibbs en ergies of the cluster formation $\left(\Delta G_{F O R M}\right)$ were calculated at the MP2/cc-pVDZ level using the rigid rotor harmonic oscillator ideal gas approximation. The interaction energy of the base '-water complexes (monohydration) was determined at the RI-MP2/ TZVPP level with the inclusion of a basis set superposition error ${ }^{20}$ and deformation energy. All calculations were performed using Gaussian $03^{21,22}$, and TURBOMOLE programs ${ }^{23}$.

Molecular dynamics/quenching (MD/Q) technique 24 . The MD/Q simulations were performed in the NVE microcanonical ensemble within quaternion formalism using the modified potential of Cornell et al. ${ }^{25}$ Treating the bases 
as rigid molecules is sufficiently accurate approximation for the MD/Q method, where the main goal is quite quick but solid exploring of the PES. The code uses a fifth-order predictor-corrector algorithm with a 0.5 fs integration step. The MD simulations were performed at a constant total energy corresponding to an average temperature of $298 \mathrm{~K}$. The MD run was interrupted every 1 ps, the kinetic energy was removed and the structure of the cluster with one water molecule was optimized using the conjugate gradient method. The geometry and energy in the minimum was stored, then the MD run was restarted from the point where it was interrupted.

Constants for geometrical parameters of non-canonical tautomers (not parametrized in the standard Cornell et al. ${ }^{25}$ force field) were derived from quantum chemical calculations using the recommended standard procedure ${ }^{26}$. The atomic charges of the tautomers were generated using the restrained-electrostatic-potential fitting procedure ${ }^{27,28}$ (RESP) at the HF/6-31G* level.

Self-consistent reaction field - continuum and hybrid approaches. Bulk water was modeled with a continuum model based on the C-PCM (COSMO) $)^{3-5}$ methodology implemented in Gaussian $03^{22}$. The cavity was described by UAHF radii ${ }^{29}$ (United Atoms radii optimized for HF/6-31G* level of theory). In the case of the hybrid method, the solvation-first-shell effect was approximated considering one explicit water molecule. In all cases, we adopted the following strategy concerning the choice of geometry for C-PCM calculations: The geometry of isolated tautomers (i.e. without considering any explicit water molecule) and also of their clusters with one water molecule was optimized in the continuum solvent at the B3LYP/6-31G* level using standard Gaussian 03 parameters and the recommended optimization strategy ${ }^{3}$ (iterative method, preconditioning, tessarea ${ }^{2} 0.4 \AA$ ). Additional nonelectrostatic first derivatives (related to cavitation, dispersion and repulsion energies) were included in the self-consistent reaction field (SCRF) procedure. Reliable solvation Gibbs energies were obtained when the geometry optimization was followed by a single-point calculation at the HF/6-31G*/UAHF level.

The molecular dynamics-thermodynamic integration method was applied to calculate the relative Gibbs energy of hydration $\left(\Delta \Delta G_{H Y D}\right)$. All calculations were performed using the GROMACS molecular modeling package $\mathrm{e}^{30,31}$ with our own code implementing the TI method. Soft core ${ }^{32}$ potential scaling was used systematically. All other details of the simulations have been presented in our previous studies ${ }^{10-13}$. 


\section{STRATEGY}

The hybrid model approximates the solvation-first-shell effect by including one or more explicit water molecules in a continuum solvent in order to describe specific hydration. Inclusion of only one water molecule was considered in this paper. According to our previous studies the main and the highest specific hydration arises from the first water molecule. Two and more water molecules around the base start to cluster together rather than create some specific single interaction with bases. Moreover there are too many structures with two water molecules that it would be very difficult to find a criterion for specific hydration what is crucial in our method.

First, all hydration positions of a base must be known which requires determination of the potential energy surface (PES) of the base-one water molecule cluster. The MD/quenching technique was utilized to explore the PES. The second step must determine which structures fulfil the criteria for specific hydration. Two different criteria were considered:

a) The hydration is always specific. Only the most populated structure (with the largest $\Delta \mathrm{G}_{\mathrm{FORM}}$ ) for each of the tautomers was considered. The value of $\Delta \mathrm{G}_{\mathrm{HYD}}$ is obtained as a sum of $\Delta \mathrm{G}_{\mathrm{HYD}}{ }^{\mathrm{COSMO}}$ (the base- $\mathrm{H}_{2} \mathrm{O}$ complex) and $\Delta \mathrm{E}$ (the base- $\mathrm{H}_{2} \mathrm{O}$ complex). Finally, the COSMO hydration Gibbs energy of an isolated water molecule $\Delta \mathrm{G}_{\mathrm{HYD}} \operatorname{cOSMO}\left(\mathrm{H}_{2} \mathrm{O}\right)$ was subtracted.

b) The $\Delta G_{F O R M}$ of the base-water complex was chosen as a criterion for specific hydration. The hydration of a base is considered to be specific if the value of $\Delta \mathrm{G}_{\mathrm{FORM}}$ of the complex is by $1 \mathrm{kcal} / \mathrm{mol}$ (or more) smaller than that of the water dimer $\left(\Delta \mathrm{G}_{\mathrm{FORM}}\left(\right.\right.$ base- $\left.\left.\mathrm{H}_{2} \mathrm{O}\right)+1 \leq \Delta \mathrm{G}_{\mathrm{FORM}}\left(\mathrm{H}_{2} \mathrm{O}-\mathrm{H}_{2} \mathrm{O}\right)\right)$; i.e. formation Gibbs energy of the base-water cluster is more favourable than that of the water dimer. When this criterion is fulfilled, the value of $\Delta G_{H Y D}$ is obtained in the same way as in the previous case a); if the criterion is not fulfilled, the hydration is not considered and $\Delta G_{H Y D}$ is equal to $\Delta G_{H Y D}{ }^{\text {COSMO }}$ of a bare base.

\section{RESULTS AND DISCUSSION}

Table I shows relative Gibbs energies in the gas phase, relative Gibbs energies of the monohydrate complex formation and relative hydration Gibbs energies for various tautomers of adenine, cytosine, guanine, thymine, uracil and isoguanine. The hybrid model results in columns a and b refer to criteria a) and b) described above. Figures 1 and 2 present the most stable structures for various monohydrated tautomers. 
TABLE I

Relative Gibbs energies in the gas phase $(\Delta G)$, relative Gibbs energies of the complex formation $\left(\Delta \Delta \mathrm{G}_{\mathrm{FORM}}\right)$ and relative hydration Gibbs energies $\left(\Delta \Delta \mathrm{G}_{\mathrm{HYD}}\right)$ of the tautomers studied (in $\mathrm{kcal} / \mathrm{mol}$ )

\begin{tabular}{|c|c|c|c|c|c|c|c|}
\hline \multirow{2}{*}{ Base } & \multirow{2}{*}{ Structure ${ }^{a}$} & \multirow{2}{*}{$\Delta \mathrm{G}$} & \multirow{2}{*}{$\Delta \Delta \mathrm{G}_{\mathrm{FORM}}{ }^{\mathrm{b}}$} & \multirow{2}{*}{$\Delta \Delta \mathrm{G}_{\mathrm{HYD}} \mathrm{COSMOC}$} & \multicolumn{2}{|c|}{$\Delta \Delta G_{H Y D}$ COSMO-HYBRID d } & \multirow{2}{*}{$\Delta \Delta \mathrm{G}_{\mathrm{HYD}}{ }^{\mathrm{Tl} \mathrm{e}}$} \\
\hline & & & & & 1 & 2 & \\
\hline \multirow{9}{*}{ Adenine } & a9 & 0.0 & 0.0 & 0.0 & 0.0 & 0.0 & 0.0 \\
\hline & al & 18.4 & -6.1 & -13.4 & -14.9 & -14.9 & -11.5 \\
\hline & a17r & 16.8 & 0.4 & -7.3 & -8.0 & -8.0 & -7.8 \\
\hline & a19r & 11.8 & -0.3 & -4.1 & -4.2 & -4.2 & -4.0 \\
\hline & a3 & 8.5 & -1.6 & -4.6 & -4.9 & -4.9 & -5.0 \\
\hline & a37l & 17.8 & -3.0 & -4.4 & -7.4 & -7.4 & -5.1 \\
\hline & a39r & 30.5 & -1.2 & -14.6 & -15.6 & -15.6 & -12.2 \\
\hline & a7 & 7.3 & 0.6 & -6.8 & -3.4 & -3.4 & -4.7 \\
\hline & a79l & 37.0 & -7.6 & -14.7 & -18.6 & -18.6 & -21.3 \\
\hline \multirow[t]{5}{*}{ Cytosine } & $\mathrm{cl}$ & 0.0 & 0.0 & 0.0 & 0.0 & 0.0 & 0.0 \\
\hline & $\mathrm{c} 2 \mathrm{a}$ & -2.2 & 0.8 & 6.5 & 7.5 & 6.1 & 3.7 \\
\hline & $c 2 b$ & -1.5 & 1.4 & 6.0 & 6.4 & 5.5 & 7.3 \\
\hline & c3a & 2.0 & 0.4 & 4.3 & 0.9 & 3.9 & 3.8 \\
\hline & $c 3 b$ & 0.5 & 0.5 & 5.2 & 5.2 & 4.7 & 4.7 \\
\hline \multirow[t]{7}{*}{ Guanine } & g19 & 0.0 & 0.0 & 0.0 & 0.0 & 0.0 & 0.0 \\
\hline & g17 & 0.3 & -0.7 & 1.5 & -0.1 & -0.1 & -0.9 \\
\hline & g39 & 19.0 & -0.7 & -12.7 & -11.4 & -11.4 & -24.8 \\
\hline & g37 & 7.2 & -1.7 & -1.5 & -3.9 & -3.9 & -18.5 \\
\hline & g79 & 23.2 & -2.1 & -10.6 & -11.1 & -11.1 & -30.7 \\
\hline & g7o2 & 4.5 & 1.0 & 5.1 & 3.8 & 3.7 & 3.1 \\
\hline & g9o2 & 1.0 & 1.8 & 6.8 & 6.0 & 5.4 & 5.6 \\
\hline \multirow[t]{7}{*}{ Thymine } & $\mathrm{t} 1$ & 0.0 & 0.0 & 0.0 & 0.0 & 0.0 & 0.0 \\
\hline & t1o2r & 9.8 & 0.3 & 0.1 & 2.5 & 0.1 & 1.0 \\
\hline & t1o4l & 22.3 & -1.5 & -4.6 & -5.3 & -6.5 & -5.5 \\
\hline & t3o2l & 18.0 & -2.6 & -5.7 & -6.5 & -7.7 & -2.5 \\
\hline & $\mathrm{t} 304 \mathrm{r}$ & 12.9 & -1.4 & -4.0 & -4.1 & -5.2 & -3.5 \\
\hline & to $2104 r$ & 12.0 & 2.2 & 0.1 & 0.6 & 0.1 & 3.0 \\
\hline & to $2 r o 4 r$ & 10.9 & -0.6 & 1.3 & 1.5 & 0.4 & 3.9 \\
\hline \multirow[t]{7}{*}{ Uracil } & u1 & 0.0 & 0.0 & 0.0 & 0.0 & 0.0 & 0.0 \\
\hline & ulo2r & 10.3 & -1.3 & 0.4 & -0.9 & -0.3 & 0.8 \\
\hline & ulo4l & 20.8 & -2.5 & -7.3 & -9.2 & -8.7 & -6.5 \\
\hline & u3o21 & 18.7 & -2.5 & -5.7 & -6.6 & -6.0 & -3.2 \\
\hline & u3o4r & 12.1 & -1.1 & -3.1 & -3.5 & -2.9 & -3.7 \\
\hline & uo2lo4r & 11.7 & 1.5 & 1.2 & 0.8 & 1.2 & 2.3 \\
\hline & uo2ro4r & 10.6 & -0.4 & 2.1 & 1.8 & 2.3 & 3.1 \\
\hline \multirow[t]{4}{*}{ Isoguanine } & aol & 0.0 & 0.0 & 0.0 & 0.0 & 0.0 & 0.0 \\
\hline & ao7 & 28.6 & 0.1 & -21.7 & -22.0 & -22.0 & -20.3 \\
\hline & c37 & 38.8 & -6.3 & -20.4 & -20.7 & -20.7 & -24.7 \\
\hline & t37 & 51.0 & 0.8 & -30.8 & -29.7 & -29.6 & -31.5 \\
\hline
\end{tabular}

a Figs 1 and 2. ${ }^{\mathrm{b}} \Delta \mathrm{G}_{\mathrm{FORM}}$ of water dimer, a9, c1, g19, t1, u1 and aol amounts to 4.85, 2.97, 3.62, 2.88, 4.02, 3.93 and $1.61 \mathrm{kcal} / \mathrm{mol}$. ' COSMO method used for bare tautomers. ${ }^{\mathrm{d}} \mathrm{Hy}$ brid model, 1- the hydration of a base is always considered as specific, 2- the hydration of a base is considered being specific if the water dimer criterion is fulfilled. ${ }^{\mathrm{e}}$ The thermodynamic integration method. 
By comparing the values in columns 1, 4, 5, 6 and 7 we can deduce the role of the solvent in the stability of various tautomers. In the following paragraphs, single NA bases will be discussed.

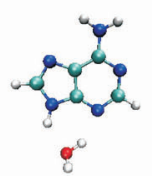

a9

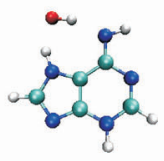

a371



$\mathrm{c} 2 \mathrm{a}$

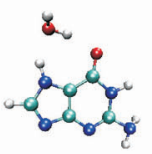

g17

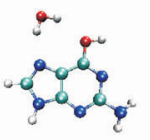

g9o2



a1



a39r

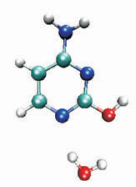

$c 2 b$



g39



a17r

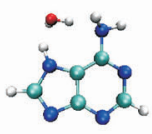

a7



c3a

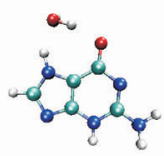

g37

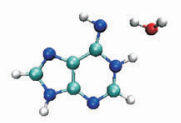

a19r

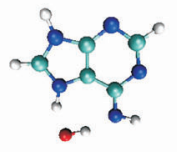

a791

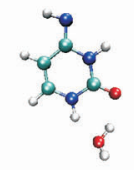

$c 3 b$

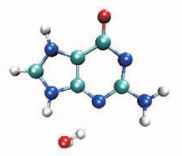

g79 g19



a3

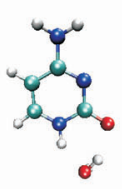

c1
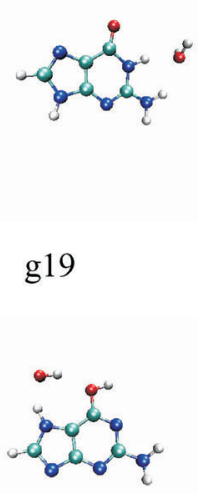

g7o2

FIG. 1

The most populated structures of each adenine, cytosine and guanine tautomers optimized at the MP2/cc-pVDZ level of theory 
Adenine. Based on the TI results (column 7 in Table I), adenine tautomers were hydrated in the following decreasing order: a79l >a39r $>$ al $>a 17 r>$ a37l >a3 >a7 >a19r >a9. The bare continuum model (column 4 in Table I) gave similar relative results and the difference concerned the a7, a3 and a37l tautomers (i.e. the order is a79l >a39r >al >a17r >a7 >a3 >a37l > a19r > a9). However, the differences between the $\mathrm{TI}$ and COSMO results for these tautomers were small $(2.1,0.4$ and $0.7 \mathrm{kcal} / \mathrm{mol}$, respectively). Only for the a79l tautomer was the COSMO value considerably smaller (by $6.6 \mathrm{kcal} / \mathrm{mol})$. The monohydration Gibbs energy of various adenine tautomers was significantly smaller than that of the water dimer, the results

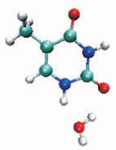

tl

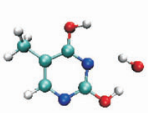

to $2104 r$

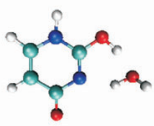

u3o21

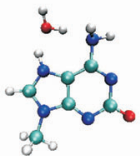

ao 7

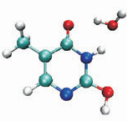

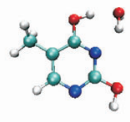

t1o2r

to 2 ro $4 \mathrm{r}$

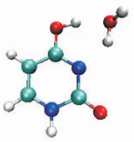

u3o4r

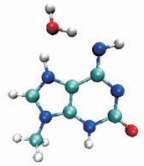

c37

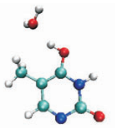

t1o41

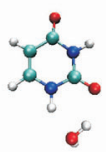

u1

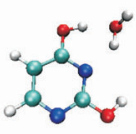

uo2lo4r



t3o 21

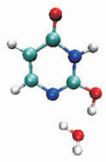

u1o2r



$\mathrm{t} 3 \mathrm{o} 4 \mathrm{r}$

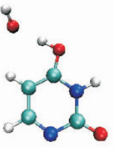

u 1041

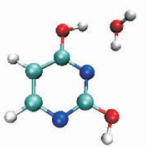

uo2ro4r aol

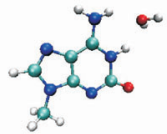

FIG. 2

The most populated structure of thymine, uracil and isoguanine tautomers optimized at the MP2/cc-pVDZ level of theory 
in columns 5 and 6 (hybrid model) are identical. When the hybrid model was adopted (columns 5 and 6 in Table I), the tautomers were hydrated in the following decreasing order: a79l >a39r >a1 >a17r >a37l >a3 >a19r > a7 $>$ a9. The respective order was similar to that for the TI method, only the a7 and a19r tautomers were exchanged. The gap between $\mathrm{TI}$ and COSMO hybrid results for the a79l tautomer also became smaller $(2.7 \mathrm{kcal} / \mathrm{mol})$ and the absolute average error (AAE) slightly decreased (from 1.8 to $1.7 \mathrm{kcal} / \mathrm{mol}$; cf. Table II). The hybrid model brought the COSMO values and the relative order of adenine tautomers closer to the TI values.

Cytosine. The $\mathrm{TI}$ results indicate that the canonical tautomer cl is hydrated better than other cytosine tautomers. A similar conclusion was obtained by the COSMO calculations. Based on TI results, tautomers were hydrated in this decreasing order: $c 1>c 2 a>c 3 a>c 3 b>c 2 b$. A continuum model gave similar relative results and the only difference concerned the c2a tautomer, which was the second in the TI series and the last one in the COSMO series. However, the difference between the $\mathrm{TI}$ and COSMO results for this tautomer was less than $3 \mathrm{kcal} / \mathrm{mol}$.

Application of the hybrid model to the cytosine tautomers was more difficult than in the previous case. The monohydration was less specific and considerably weaker compared with adenine tautomers. Consideration of

\section{TABLE II}

The absolute average error (AAE) of the relative hydration Gibbs energies $\left(\Delta \Delta \mathrm{G}_{\mathrm{HYD}}\right)$ obtained by COSMO and the hybrid model compared with the MD-TI (in $\mathrm{kcal} / \mathrm{mol}$ )

Hybrid model $^{a}$

Base

COSMO

$a^{b}$

$b^{c}$

Adenine

1.8

1.7

1.7

Cytosine

1.3

2.0

1.1

Guanine

9.1

8.3

8.2

Thymine

1.8

1.8

2.5

Uracil

1.1

1.8

1.5

Isoguanine

2.1

2.5

2.5

Average

2.9

3.0

2.9

${ }^{a}$ Hybrid model, see strategy. ${ }^{b}$ The hydration of a base is always considered as specific. ${ }^{c}$ The hydration of a base is considered to be specific only if the water dimer criterion is fulfilled. 
the water dimer criterion b) is thus more useful. Although the relative order of cytosine tautomers obtained by the hybrid model was the same in both cases, the AAE for the criterion b) was smaller than that for bare COSMO (1.1 vs $1.3 \mathrm{kcal} / \mathrm{mol}$; cf. Table II).

Guanine. Based on the TI results, guanine tautomers were hydrated in the following decreasing order: g79>g39>g37>g17>g19>g7o2 > g9o2. The continuum model gave different results and the g19 and g17 tautomers were exchanged, which was also true for the g39 and g79 tautomers (i.e. the order is g39 > g79>g37>g19>g17>g7o2 > g9o2). Despite the quite good qualitative values, the absolute values obtained by the TI and COSMO methods differed considerably (as much as $20 \mathrm{kcal} / \mathrm{mol}$ ).

When applying the hybrid model, the tautomers were hydrated in the following decreasing order: g39>g79>g37>g17>g19>g7o2 > g9o2. The use of the hybrid model lowered the AAE from 9.1 to 8.3 (criterion a)) or 8.2 (criterion b)) and al so changed the order of the g17 and g19 tautomers.

Thymine. According to the TI results, thymine tautomers were hydrated in the following decreasing order: tlo4l $>$ t3o4r $>$ t3o2l $>$ t1 $>$ t1o2r $>$ to $2104 r>$ to 2 ro $4 r$. The continuum model gave slightly different results and the difference concerned the t1o4l, t3o4r, t3o2l and to $2104 r$ tautomers (i.e.

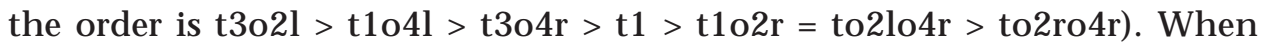
using the hybrid model with the water dimer criterion b), the order did not change. The hybrid model with criterion a) gave results which were usually closer to the $\mathrm{TI}$ results; the AAE was comparable for bare COSMO and the hybrid model with criterion a).

Uracil. Based on the TI results, the uracil tautomers were hydrated in the following decreasing order: u104l > u3o4r > u3o2l > u1 >u102r > uo2lo4r $>$ uo2ro4r. A continuum model gave similar relative results and the only difference concerned the $\mathrm{u} 304 \mathrm{r}$ and $\mathrm{u} 302 \mathrm{l}$ tautomers, which were exchanged in the COSMO series (i.e. the order is u104l > u3o2l > u3o4r > u1 >u1o2r $>$ uo2lo4r $>$ uo2ro4r). The absolute COSMO values were in a good agreement with the TI ones. The AAE of the COSMO method was only $1.1 \mathrm{kcal} / \mathrm{mol}$. The hybrid model did not shift the COSMO results closer to the TI results and the AAE increased. Not only the u3o4r and u3o2l tautomers but even the $u 1$ and u1o2r were exchanged (i.e. the order is u104l > u3o2l > u3o4r $>$ $u 102 r>u 1>$ uo2lo4r $>$ uo2ro4r) in the series when the hybrid model was used. Using the water dimer criterion yielded results, which were closer to the TI numbers.

Isoguanine. The $\mathrm{TI}$ results indicated that isoguanine tautomers are hydrated in the following decreasing order: t37>c37>ao7>aol. The ao7 and c37 tautomers were exchanged in the COSMO series (i.e. the order is 
t37 > ao7 >c37 >ao1). The AAE increased if both hybrid models were used but the change in the COSMO results caused by using the hybrid model was less than $1 \mathrm{kcal} / \mathrm{mol}$ for all isoguanine tautomers and the relative order did not change (i.e. the order is t37 > ao7 >c37 >aol).

\section{CONCLUSION}

The hybrid model considering the water dimer criterion gives better results than the bare COSMO for adenine, cytosine and guanine while for thymine, uracil and isoguanine the opposite is true. When the simple hybrid model is used (i.e. criterion a) is considered), better results are obtained only for adenine and guanine. Averaging the AAE for all NA bases yields the same values for the hybrid model with criterion b) and for the bare COSMO (2.9) and a slightly higher value for the hybrid model with criterion a) (3.0).

It can thus be concluded that introduction of specific hydration, which is physically fully adequate, does not bring any improvement over bare COSMO. On the other hand, it does not cause any significant deterioration and it should not be excluded.

Although the bare COSMO and MD-TI results are in a good agreement in our calculations, some minor differences still remain. We believe that correctly described specific hydration can minimize this difference. Furthermore many other system different from our can require such hydration description in order to posses reliable results, comparable to MD-TI results.

This study was supported by the Ministry of Education, Youth and Sports of the Czech Republic (grant LC 512) and by the Grant Agency of the Czech Republic (grant No. 203/05/0009); it was also a part of the research project Z4 055 0506. J.R. also acknowledges the Grant 203/05/H001.

\section{REFERENCES}

1. Zhanpeisov N. U., Leszczynski J.: J. Phys. Chem A 1998, 102, 6167.

2. Zhanpeisov N. U., Leszczynski J.: J. Mol. Struct. (THEOCHEM) 1999, 487, 107.

3. Cossi M., Rega N., Scalmani G., Barone V.: J. Comput. Chem. 2003, 24, 669.

4. Barone V., Cossi M., Tomasi J.: J. Comput. Chem. 1998, 19, 404.

5. Klamt A., Krooshof G. J. P., Taylor R.: AIChE J. 2002, 48, 2332.

6. Tomasi J., Mennucci B., Cammi R.: Chem. Rev. 2005, 105, 2999.

7. da Silva C. O., Mennucci B., Vreven T.: J. Phys. Chem. A 2003, 107, 6630.

8. Sicinska D., Paneth P., Truhlar D. G.: J. Phys. Chem. B 2002, 106, 2708.

9. Šponer J., Hobza P.: Collect. Czech. Chem. Commun. 2003, 68, 2231.

10. Hanus M., Ryjáček F., Kabeláč M., Kubař T., Bogdan T. V., Trygubenko S. A., Hobza P.: J. Am. Chem. Soc. 2003, 125, 7678. 
11. Hanus M., Kabeláč M., Rejnek J., Ryjáček F., Hobza P.: J. Phys. Chem. B 2004, 108, 2087.

12. Rejnek J., Hanus M., Kabeláč M., Ryjáček F., Hobza P.: Phys. Chem. Chem. Phys. 2005, 7, 2006.

13. Trygubenko S. A., Bogdan T. V., Rueda M., Orozco M., Luque F. J., Šponer J., Slavíček P., Hobza P.: Phys. Chem. Chem. Phys. 2002, 4, 4192.

14. Orozco M., Luque F. J.: Chem. Rev. 2001, 101, 203.

15. Aleman C.: Chem. Phys. Lett. 1999, 302, 461.

16. Aleman C.: Chem. Phys. 2000, 253, 13.

17. Pliego J. R., Riveros J. M.: J. Phys. Chem. A 2001, 105, 7241.

18. Pliego J. R., Riveros J. M.: J. Phys. Chem. A 2002, 106, 7434.

19. Feyereisen M., Fitzgerald G., Komornicki A.: Chem. Phys. Lett. 1993, 208, 359.

20. Boys S. F., Bernardi F.: Mol. Phys. 1970, 19, 553.

21. Frisch M. J., Trucks G. W., Schlegel H. B., Scuseria G. E., Robb M. A., Cheeseman J. R., Zakrzewski V. G., Montgomery J. A., Stratmann R. E., Burant J. C., Dapprich S., Millam J. M., Daniels A. D., Kudin K. N., Strain M. C., Farkas O., Tomasi J., Barone V., Cossi M., Cammi R., Mennucci B., Pomelli C., Adamo C., Clifford S., Ochterski J., Petersson G. A., Ayala P. Y., Cui Q., Morokuma K., Malick D. K., Rabuck A. D., Raghavachari K., Foresman J. B., Cioslowski J., Ortiz J. V., Stefanov B. B., Liu G., Liashenko A., Piskorz P., Komaromi I., Gomperts R., Martin R. L., Fox D. J., Keith T., Al-Laham M. A., Peng C. Y., Nanayakkara A., Gonzalez C., Challacombe M., Gill P. W., Johnson B. G., Chen W., Wong M. W., Andres J. L., Head-Gordon M., Replogle E. S., Pople J. A.: Gaussian 03. Gaussian Inc., Pittsburgh (PA) 1998.

22. Frisch M. J., Trucks G. W., Schlegel H. B., Scuseria G. E., Robb M. A., Cheeseman J. R., Montgomery J. A., Vreven T., Jr., Kudin K. N., Burant J. C., Millam J. M., Iyengar S. S., Tomasi J., Barone V., Mennucci B., Cossi M., Scalmani G., Rega N., Petersson G. A., Nakatsuji H., Hada M., Ehara M., Toyota K., Fukuda R., Hasegawa J., Ishida M., Nakajima T., Honda Y., Kitao O., Nakai H., Klene M., Li X., Knox J. E., Hratchian H. P., Cross J. B., Adamo C., Jaramillo J., Gomperts R., Stratmann R. E., Yazyev O., Austin A. J., Cammi R., Pomelli C., Ochterski J. W., Ayala P. Y., Morokuma K., Voth G. A., Salvador P., Dannenberg J. J., Zakrzewski V. G., Dapprich S., Daniels A. D., Strain M. C., Farkas O., Malick D. K., Rabuck A. D., Raghavachari K., Foresman J. B., Ortiz J. V., Cui Q., Baboul A. G., Clifford S., Cioslowski J., Stefanov B. B., Liu G., Liashenko A., Piskorz P., Komaromi I., Martin R. L., Fox D. J., Keith T., Al-Laham M. A., Peng C. Y., Nanayakkara A., Challacombe M., Gill P. M. W., Johnson B., Chen W., Wong M. W., Gonzalez C., Pople J. A.: Gaussian 03. Gaussian, Inc., Pittsburgh (PA) 2003.

23. Ahlrichs R., Bar M., Haser M., Horn H., Kolmel C.: Chem. Phys. Lett. 1989, 162, 165.

24. Kratochvil M., Engkvist O., Sponer J., Jungwirth P., Hobza P.: J. Phys. Chem. A 1998, 102, 6921.

25. Cornell W. D., Cieplak P., Bayly C. I., Gould I. R., Merz K. M., Ferguson D. M., Spellmeyer D. C., Fox T., Caldwell J. W., Kollman P. A.: J. Am. Chem. Soc. 1995, 117, 5179.

26. Case D. A., Cheatham III T. E., Simmerling C. L., Wang J., Duke R. E., Luo R., Merz K. M., Wang B., Pearlman D. A., Crowley M., Brozell S., Tsui V., Gohlke H., Mongan J., Hornak V., Cui G., Beroza P., Schafmeister C., Caldwell J. W., Ross W. S., Kollman P. A.: Amber 8: Manual and help page, 2004, http://amber.scripps.edu/.

27. Bayly C. I., Cieplak P., Cornell W. D., Kollman P. A.: J. Phys. Chem. 1993, 97, 10269.

28. Cornell W. D., Cieplak P., Bayly C. I., Kollman P. A.: J. Am. Chem. Soc. 1993, 115, 9620. 
29. Gaussian 03 on-line help, http://www.gaussian.com/g_ur/g03mantop.htm. Accessed 24.1.03.

30. Lindahl E., Hess B., van der Spoel D.: J. Mol. Model. 2001, 7, 306.

31. Berendsen H. J. C., Vanderspoel D., Vandrunen R.: Comput. Phys. Commun. 1995, 91, 43.

32. Beutler T. C., Mark A. E., Vanschaik R. C., Gerber P. R., Vangunsteren W. F.: Chem. Phys. Lett. 1994, 222, 529. 